\title{
i. Mechanisms of a locally adaptive shift in allocation among growth, reproduction, and herbivore resistance in Mimulus guttatus
}

ii. Running Title: Trade-offs underlying local adaptation

iii. Authors: David B. Lowrya, ${ }^{\mathrm{a}, \mathrm{c}}$, Damian Popovic $^{\mathrm{a}, \mathrm{b}}$, Darlene J. Brennan ${ }^{\mathrm{a}}$, Liza M. Holeski ${ }^{\mathrm{d}}$

iv. aDepartment of Plant Biology, Michigan State University, East Lansing, MI, USA

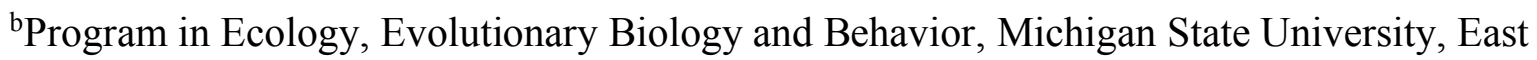

Lansing, MI 48824, USA

cPlant Resilience Institute, Michigan State University, East Lansing, MI 48824, USA

${ }^{\mathrm{d} D e p a r t m e n t ~ o f ~ B i o l o g i c a l ~ S c i e n c e s, ~ N o r t h e r n ~ A r i z o n a ~ U n i v e r s i t y, ~ F l a g s t a f f, ~ A Z, ~} 86011$

v. Corresponding author: David B. Lowry, dlowry@msu.edu

vi. Author Contributions: DL and DP designed the experiments; DL, DP and DB conducted the experiments; LH conducted the analyses of herbivore resistance compounds; DL and LH wrote the manuscript.

vii. Acknowledgements: We would like to thank Sol Chavez for assisting with the quantification of PPGs. Seed collections were originally made possible by permission from the state parks of Oregon and California. Funding for this research was provided by Michigan State University through a startup package to DBL.

viii. Raw data from experiments will be deposited at Dryad upon publication 
1 Mechanisms of a locally adaptive shift in allocation among growth, reproduction, and

2 herbivore resistance in Mimulus guttatus

4 ABSTRACT

5 Environmental gradients can drive adaptive evolutionary shifts in plant resource allocation

6 among growth, reproduction, and herbivore resistance. However, few studies have attempted to

7 connect these adaptations to underlying physiological and genetic mechanisms. Here, we

8 evaluate potential mechanisms responsible for a coordinated locally adaptive shift between

9 growth, reproduction, and herbivore defense in the yellow monkeyflower, Mimulus guttatus.

10 Through manipulative laboratory experiments we found that gibberellin (GA) growth hormones

11 may play a role in the developmental divergence between perennial and annual ecotypes of $M$.

12 guttatus. Further, we detected an interaction between a locally adaptive chromosomal inversion,

13 DIV1, and GA addition. This finding is consistent with the inversion contributing to the

14 evolutionary divergence between inland annual and coastal perennial ecotypes by reducing GA

15 biosynthesis/activity in perennials. Finally, we found evidence that the DIVI inversion is

16 partially responsible for a coordinated shift in the divergence of growth, reproduction, and

17 herbivore resistance traits between coastal perennial and inland annual M. guttatus. The

18 inversion has already been established to have a substantial impact on the life-history shift

19 between long-term growth and rapid reproduction. Here, we demonstrate that the DIV1 inversion

20 also has sizable impacts on both the total abundance and composition of phytochemical

21 compounds involved in herbivore resistance.

22 Key Words: Chromosomal Inversion, Ecotype, Gibberellin, Mimulus guttatus, Supergene,

23 Trade-offs 


\section{INTRODUCTION}

25 One of the fundamental tenets of evolutionary biology is that adaptation of organisms to specific

26 environmental conditions inevitability results in a fitness trade-off. Trade-offs often manifest in

27 the form of a cost, such that organisms that become adapted to one set of environmental

28 conditions will be at a disadvantage in alternative environments (Futuyma and Moreno 1988;

29 Whitlock 1996). The idea of trade-offs involved in adaptation and ecological specialization has

30 been borne out in a wide range of evolutionary scenarios, including predator-prey relationships

31 and host-races formation in insect herbivores (Futuyma and Moreno 1988; Kawecki 1998;

32 Svanback and Eklov 2003; Forister et al. 2012). A common source of ecological specialization

33 and consequent trade-offs is the process of local adaptation across environmental gradients

34 (Kawecki and Ebert 2004; Hereford 2009).

36 Local adaption across environmental gradients can lead to shifts in the allocation of resources to

37 long-term growth (survival) and reproduction (fecundity; Clausen and Hiesey 1958; Lowry

38 2012; Friedman and Rubin 2015). Those shifts in life-history strategy along environmental

39 gradients can also have major impacts on allocation to herbivore defense (Hahn and Maron

40 2016). However, there appears to be key differences in how resources are allocated across

41 environmental gradient for interspecific and intraspecific comparisons. Interspecific variation in

42 plant species typically fits well with the resource allocation hypothesis (Coley et al. 1985), where

43 low resource environments tend to be composed of slower growing better defended species while

44 high resource environments promote faster growing poorly defended plants (Endara and Coley

45 2011). In contrast, intraspecific variation along environmental gradients is far less consistent and

46 more often than not contradicts the predictions of the resource allocation hypothesis (Hahn and 
47 Maron 2016). One common pattern for intraspecific plant variation is a positive relationship

48 between the length of the growing season along an environmental gradient and the level of

49 herbivore resistance (Hahn and Maron 2016; Kooyers et al. 2017). This pattern could be driven

50 by plants having more time to allocate resources to leaf production and defense, greater

51 herbivore pressure in habitats with longer growing seasons, and/or a greater apparency of plants

52 with longer growing seasons (Feeny 1976; Mason and Donovan 2015; Hahn and Maron 2016;

53 Kooyers et al. 2017). Another important factor to consider is allocation to reproduction

54 (fecundity), which frequently trades off with constitutive and/or induced herbivore resistance

55 (Agren and Schemske 1993; Heil and Baldwin 2002; Strauss et al. 2002; Stowe and Marquis

56 2011; Cipollini et al. 2014).

Achieving an evolutionary optimum in how resources are allocated to growth, reproduction, and

59 defense will depend on the nature of all environmental challenges faced by each local population

60 (Rhoades 1979; Rausher 1996; Hamilton et al. 2001; Strauss et al. 2002; Stamp 2003; Karban

61 2011; Cipollini et al. 2014; Jensen et al. 2015; Smilanich et al. 2016). Despite the development

62 of multiple ecological and evolutionary hypotheses that postulate a relationship between growth,

63 reproduction, and resistance to herbivores (Feeny 1976; Coley et al. 1985; Rhoades 1979; Herms

64 and Mattson 1992; Strauss et al. 2002; Stamp 2003, Fine et al. 2006; Agrawal et al. 2010;

65 Cipollini et al. 2014; Hahn and Maron 2016), these hypotheses do not make any predictions

66 about the underlying molecular mechanisms that mediate these relationships. The genetic

67 mechanisms responsible for trade-offs among growth, reproduction, and resistance are just

68 beginning to be elucidated in model systems (Lorenzo et al. 2004; Yang et al. 2012; Kerwin et al. 
2015; Campos et al. 2016; Havko et al. 2016; Major et al. 2017; Howe et al. 2018; Rasmann et

al. 2018), but have yet to be evaluated in the evolutionary context of local adaptation.

71 Recent studies have shown that changes in the allocation of resources to growth versus resistance

72 are made through a set of interacting gene networks (Karzan and Manners 2012; Huot et al.

73 2014; Campos et al. 2016; Havko et al. 2016). Jasmonates (JA) are key regulatory hormones

74 involved in the response of plants to herbivore attack (Zhang and Turner 2008; Havko et al.

75 2016). While JA production increases herbivore defenses, it also inhibits plant growth through

76 interactions with other gene networks (Zhang and Turner 2008; Yan et al. 2007; Karzan and

77 Manners 2012; Yang et al. 2012). For example, the critical cross-talk between downstream genes

78 in the JA pathway (JAZ genes) and Gibberellin (GA) pathway (DELLA genes) are thought to

79 play a pivotal role in mediating resource allocation (Yang et al. 2012; Hou et al. 2013; Havko et

80 al. 2016).

82 Here, we focus on understanding the physiological and genetic mechanisms underlying shifts in

83 allocation to growth, reproduction, and defense for local adapted populations of the yellow

84 monkeyflower Mimulus guttatus. The availability of soil water is a key driver of local adaptation

85 in the M. guttatus species complex (Hall and Willis 2006; Lowry et al. 2008; Ferris et al. 2017).

86 The coastal habitats of California and Oregon have many wet seeps and streams that are

87 maintained year-round as a result of persistent summer oceanic fog and cool temperatures (Hall

88 and Willis 2006; Lowry et al. 2008; Lowry and Willis 2010). All coastal populations of $M$.

89 guttatus that reside in those habitats have a late-flowering life-history strategy. These coastal

90 perennial populations thus, make a long-term investment in growth over reproduction (Hall and

91 Willis 2006; Lowry et al. 2008; Hall et al. 2010; Baker and Diggle 2011; Baker et al. 2012). That 
92 investment in growth manifests through the production of many vegetative lateral stolons,

93 adventitious roots, and leaves in coastal perennial plants. In contrast, the vast majority of nearby

94 inland populations of M. guttatus in the coastal mountain ranges reside in habitats that dry out

95 completely during summer months. These inland populations have evolved a rapid growth,

96 drought escape annual life-history strategy. Instead of investing in vegetative lateral stolons, the

97 axillary branches of inland plants are mostly upcurved and typically produce flowers quickly

98 (Lowry et al. 2008; Lowry and Willis 2010; Friedman et al. 2015). Further, inland plants invest

99 less into the production of leaves before flowering than coastal perennials (Friedman et al. 2015).

100 It should be noted that a smaller number of inland populations in the coastal mountain ranges do

101 reside in rivers and perennials seeps and have a perennial life-history. Farther inland, perennial

102 populations are more common, especially in high elevation streams and hot springs of the Sierra

103 and Cascade Mountains (Oneal et al. 2014). The inland perennial plants are similar to coastal

104 perennials in overall morphology, especially in that they are more prostrate in growth habit, with

105 the production many stoloniferous branches. However, the coastal perennials differ from inland

106 perennial by being more robust in their growth form and having evolved tolerance to oceanic salt

107 spray (Lowry et al. 2009).

109 While perennial populations invest more into vegetative growth than reproductive growth, they

110 also invest more heavily in defending their vegetative tissues. Perennial populations of $M$.

111 guttatus have higher levels of both constitutive and induced defensive phenylpropanoid

112 glycoside (PPG) compounds than the annual populations when grown in a common environment

113 (Holeski et al. 2013). PPG levels have a negative relationship with the performance of multiple

114 generalist herbivores in M. guttatus (Rotter et al. 2018). This pattern of highly defended plants in 
115 wetter habitats with long growing seasons versus poorly defended plants in dry habitats with

116 short growing seasons is consistent with an optimal defense strategy: Greater allocation of

117 resources to herbivore resistance is favored in habitats with a long growing season by both a

118 greater abundance of herbivores and a lower physiological cost of producing defensive

119 compounds due to high soil water availability (Kooyers et al. 2017).

121 Two major QTLs (DIV1 and DIV2) and many minor QTLs control key traits involved in local

122 adaptation to perennial and annual habitats within the M. guttatus species complex (Hall et al.

123 2006; Lowry and Willis 2010; Hall et al. 2010; Friedman and Willis 2013; Friedman et al. 2015).

124 DIV1 has the largest effect on the most traits and has thus been more extensively studied than

$125 D I V 2 . D I V 1$ is a large paracentric chromosomal inversion that plays a pivotal role in the annual

126 versus perennial life-history divergence described above (Lowry and Willis 2010). The inversion

127 is at minimum 6.3 Mbp in length along linkage group 8 (LG8) and contains at least 785

128 annotated genes. In hybrids, DIVI has a major effect on growth rate including the adaptive

129 flowering time phenotype, explaining $21 \%$ to $48 \%$ of the divergence between inland annual and

130 coastal perennial parents (Lowry and Willis 2010). In addition to flowering time, the DIV1

131 inversion has major effects on multiple traits involved in the evolutionary shift from more

132 allocation of resources to long-term growth versus reproduction (Lowry and Willis 2010). Plants

133 with the perennial (PE) orientation of the inversion have a more prostrate growth habitat,

134 produce more lateral stolons and adventitious roots, have thicker shoots, and larger flowers than

135 plants with the annual (AN) orientation of the inversion (Lowry and Willis 2010; Friedman et al.

136 2015). A recent allele frequency outlier analysis of coastal perennial and inland annual

137 populations identified candidate genes in the gibberellin pathway that may underlie a pleiotropic 
138 shift in allocation between growth and reproduction (Gould et al. 2017). That study also found

139 evidence of recent selection on a key GA biosynthetic gene, GA20-oxidase2 (GA20ox2), within

140 the DIV1 inversion and for the Gibberellic Acid Insensitive (GAI) in the vicinity of DIV2.

142 Given the recent outlier analysis identifying divergence among genes in the GA pathway and the

143 GA pathways interaction with the JA herbivore resistance pathway, we evaluate the role of GA

144 in the divergence of growth morphology and herbivore resistance between perennial and annual

145 ecotypes of M. guttatus. We hypothesized that perennial accessions would display a greater

146 morphological response to GA addition than annual accession, as their prostrate morphology was

147 consistent with lower GA biosynthesis and/or downstream signaling activity. Further, we

148 hypothesized that the adaptive DIVI inversion contributes to the lower GA biosynthesis/activity

149 in coastal perennial plants. To test this hypothesis, we utilized near-isogenic lines (NILs) for the

150 DIV1 locus and evaluated whether there was interaction between the DIV1 inversion and GA

151 addition. If the GA biosynthesis/activity is down regulated by the perennial orientation of the

152 inversion, then we predict that the NILs containing the perennial inversion orientation will

153 respond more to the GA addition than the NILs containing the annual orientation. Finally, we

154 tested the hypothesis that the DIVI inversion is partially responsible for the evolution of locally

155 adaptive trade-offs in allocation between reproduction and defense that has been broadly

156 observed for populations of $M$. guttatus that vary in growing season length (Lowry et al. 2008;

157 Holeski et al. 2013; Kooyers et al. 2017). To test this hypothesis, we compared the

158 concentrations of PPGs between NILs containing coastal perennial and inland annual

159 orientations of the DIV1 inversion. 


\section{METHODS}

162

\section{Plant material}

164 For comparisons among ecotypes, we utilized single family population accessions derived from

165 coastal perennial, inland annual, and inland perennial populations of M. guttatus (Fig. 1). The

166 locations from where population accessions were collected are listed in Table S1. Previous

167 population structure analyses found that coastal perennial populations of $M$. guttatus are more

168 closely related to each other than they are to the inland annual populations (Lowry et al. 2008;

169 Twyford and Friedman 2015). Thus, the coastal populations collectively constitute a distinct

170 locally adapted ecotype (Lowry 2012). In contrast, population structure between inland annuals

171 and inland perennial populations is generally low (Twyford and Friedman 2015). However,

172 particular regions of the genome, including an adaptive chromosomal inversion (DIV1, discussed

173 below) are more differentiated between inland annuals and inland perennials (Oneal et al. 2014;

174 Twyford and Friedman 2015). We therefore consider inland annuals and inland perennials as

175 different ecotypes as well.

176

177 To understand the phenotypic effects of the DIV1 inversion, Lowry and Willis (2010) previously

178 created near-isogenic lines (NILs) for the inversion. The NILs are the product of crosses between

179 inbred lines from the coastal perennial SWB population and the nearby inland annual LMC

180 population. F1 hybrids were recurrently backcrossed to both of their respective parents for four

181 generations. Heterozygous fourth generation backcrosses were then self-fertilized to produce two

182 types of NILs: 1) Individuals that were homozygous for the introgressed allele of DIV1

183 (Introgression-NILs) and 2) Individuals that were homozygous for the DIV1 allele of the genetic 
184 background (henceforth referred to as Control-NILs). Comparisons between Introgression-NILs

185 and Control-NILs are ideal for testing inversion function because their genetic backgrounds are 186 nearly identical, but they are homozygous for opposite DIV1 alleles.

\section{The effects of $G A$ application on plant growth among ecotypes}

189 To evaluate whether perennial and annual plants differ in their response to GA addition, we 190 conducted a greenhouse experiment with accessions derived from five coastal perennial, four

191 inland annual, and two inland perennial populations (Table S1). Seeds were sown in Suremix soil

192 (Michigan Grower Products Inc., Galsburg, MI) and stratified at $4^{\circ} \mathrm{C}$ for two weeks. After

193 stratification, pots were moved to the Michigan State University greenhouses. Temperature was

194 set in the greenhouse room to $22^{\circ} \mathrm{C}$ days $/ 18^{\circ} \mathrm{C}$ nights. Plants were grown in 16-hour days and 8-

195 hour nights, where supplemental lighting was used during the full day period. Seedlings were

196 transplanted to individual 3.5-inch square pots filled with Suremix soil. Transplanted seedlings

197 were randomized across the experiment and randomly assigned to a GA treatment group or a

198 mock control group. After transplantation, plants were sprayed five times each, every other day,

199 with $100 \mathrm{mM}$ GA3 (GA treatment) or DI water (mock). This daily spray volume amounts to $\sim 3.5$

$200 \mathrm{~mL}$.

202 To standardize the developmental time point at which plant traits were quantified, we measured

203 the following traits on the day of first flowering: Total number of nodes on the primary shoot,

204 lengths and widths of the first three internodes, length and width of the corolla of the first open

205 flower, plant height, the total number of adventitious roots at the first node of all branches, total

206 number of stoloniferous nodes sprouting adventitious roots, total number of aerial branches, total 
number of stolons, length of the longest aerial branch, length of the longest stolon, and the length

208 and width of the longest leaf at the second node. Ten days after first flower, we quantified the

209 same traits as at first flower, with the following exceptions: Length and width of corollas were

210 not quantified, but we did count the total number of flowers.

212 Results were analyzed with JMP 14.0.0 (SAS Institute, Cary, NC). To test the hypothesis that the

213 perennials respond morphologically more to the addition of GA, we conducted principal

214 components analyses using all of the measured traits. Since many of these traits were highly

215 correlated (Table S1), we reduced the dimensionality of the data with a principal components

216 (PC) analysis. We conducted the PC analysis on correlations in JMP. We used a Scree Test

217 (Cattell 1966) to determine how many principal components to retain. To understand the effects

218 of accession, ecotype, GA treatment, and the interactions of these effects on each PC, we fit the

219 default standard least squares ANOVA model with the Fit Model platform in JMP. Each of the

220 PCs were modeled as response variables to the following fixed-effect factors and interactions:

221 accession (nested within ecotype), ecotype (coastal perennial, inland annual, inland perennial),

222 treatment (GA vs. Mock), accession x treatment, and ecotype $\mathrm{x}$ treatment. A significant ecotype

$223 \mathrm{x}$ treatment interaction would indicate that the ecotypes vary in their response to GA. Further, if

224 perennials responded more to the GA treatment it would support the hypothesis that the

225 perennials have less GA biosynthesis/activity than the annuals.

\section{Interactions of $G A$ application with the adaptive DIV1 inversion}

228 We grew coastal (SWB-S1) and inland (LMC-L1) parental inbred lines along with the NILs

229 derived from those lines in a fully randomized design in the Michigan State University 
230 greenhouses, with 16-hours of supplemental lighting. We focused on the effect of the inversion

231 in the coastal perennial genetic background, as a previous study had shown that the effect of the

232 inversion had the greatest effect in the perennial genetic background (Friedman 2014). Following

233 transplantation, seedlings were sprayed with GA or a mock water treatment every other day and

234 traits were quantified in the same way as for the comparing population accessions.

236 To establish how trait variation of the coastal and inland parental lines was influenced by the GA

237 treatment, we conducted a PC analysis of all plants in the experiment in JMP 14.0.0. As for the

238 analysis with multiple population accessions (above), we conducted principal components

239 analyses using all traits and used a Scree Test (Cattell 1966) to determine how many principal

240 components to retain. Models were fit for each PC to test the effect of the following fixed-effect

241 factors: line, treatment, and the line $\mathrm{x}$ treatment interaction. We fit models independently for the

242 parental lines and the NILs. The analysis of the parental lines was conducted to confirm that the

243 responses to GA were similar as for the population survey (above). The analysis of the NILs

244 allowed us to test whether there was a significant interaction of the inversion with the GA

245 treatment (i.e. line $\mathrm{x}$ treatment interaction). Line $\mathrm{x}$ treatment least square means were compared

246 with Tukey HSD post hoc analyses for both parental lines and NILs. A significant line $\mathrm{x}$

247 treatment interaction for the NILs, with a greater response for the introgression NILs, would

248 support the hypothesis that the perennial orientation of the DIV1 inversion reduces GA

249 biosynthesis/activity.

251 Effects of the DIV1 inversion on resistance compound concentrations 
252 To evaluate the effects of the DIV1 inversion on the production of herbivore resistance

253 compounds, we conducted an experiment using the inversion NILs. Seeds were stratified,

254 germinated, and transplanted following the same protocols as in the previous two experiments. In

255 contrast to the GA NIL experiment, we grew outbred NILs which were created by intercrossing

256 independently derived NILs because we did not have any prior data on the impacts of inbreeding

257 on PPG production. As for the GA experiment, we focused our study on the effect of the

258 inversion in the perennial genetic background. Here, we used the outbred NILs made by

259 intercrossing SWB-S2 and SWB-S3 derived coastal genetic background NILs. We used

260 intercrosses between LMC-L2 andLMC-L3 for the inland parents and between SWB-S2 and

261 SWB-S3 for the coastal perennial parent comparisons. See Lowry \& Willis (2010) for full

262 description of outbred NIL generation.

263

264 To ensure that enough leaf tissue was available for analyses, outbred NILs and outbred parents 265 were allowed to flower prior to the collections for PPG quantification. Collected leaf tissue was

266 lyophilized for two days and then shipped to Northern Arizona University for analyses. We

267 ground the leaf tissue using a $1600 \mathrm{MiniG}$ (Spex, Metuchen, New Jersey). Extractions were

268 conducted in methanol, as described in Holeski et al. 2013, 2014. We quantified PPGs using high

269 performance liquid chromatography (HPLC), via an Agilent 1260 HPLC (Agilent Technologies,

270 Santa Clara, California) with a diode array detector and Poroshell 120 EC-C18 analytical column

$271(4.6 \times 250 \mathrm{~mm}, 2.7 \mu \mathrm{m}$ particle size $)$ maintained at $30^{\circ} \mathrm{C}$. HPLC run conditions, were conducted

272 as described in Kooyers et al. (2017). We calculated concentrations of PPGs as verbascoside

273 equivalents, using a standard verbascoside solution (Santa Cruz Biotechnology, Dallas, Texas),

274 as described in Holeski et al. (2013, 2014). We compared the concentrations of total PPGs and 
275 individual PPGs with one-way ANOVAs fit in JMP 12.2.0. Post-hoc Tukey HSD Tests were

276 used to compare means of parental and NIL classes.

\section{RESULTS}

\section{The effects of $G A$ application on plant growth among ecotypes}

280 Consistent with previous studies (Hall et al. 2006; Lowry et al. 2008; Lowry and Willis 2010;

281 Oneal et al. 2014), there were large differences in morphology between coastal perennial, inland

282 annual, and inland perennial ecotypes. The perennials, especially the coastal ones, were generally

283 larger overall across a suite of traits. The perennials also all had a prostrate growth habit with

284 many lateral stolon branches that produced adventitious roots. In contrast, the inland annuals had

285 thinner shoots, smaller flowers, and primarily produced upcurved aerial branches lacking

286 adventitious roots. We reduced the dimensionality of the data using a principal components

287 analysis, retaining the first 4 PCs based on a Scree Test (Figure S1; Cattell 1966). The first four

288 PCs collectively explained $70.3 \%$ of the phenotypic variation. Most traits (32 out of 37) heavily

289 loaded (Loadings $>0.40)$ onto the first PC (Eigenvalue = 14.698; Table S2). Ecotype divergence

290 accounted for for much of the variation of PC1 $\left(F_{2,225}=211.04, P<0.0001\right.$; Figure 2A; Table 1).

291 Within ecotype, there was a significant effect of accession on PC1 $\left(F_{8,225}=23.70, P<0.0001\right)$,

292 and there was a significant effect of the GA treatment on PC1 $\left(F_{1,225}=15.22, P=0.0001\right)$. While

293 there was a significant accession $\mathrm{x}$ treatment effect for $\mathrm{PC} 1\left(F_{8,225}=2.59, P=0.0101\right)$, the

294 treatment $\mathrm{x}$ ecotype effect was not significant $(P=0.1930)$. In contrast to PC1, both of the

295 interactions were significant for PC2 (Eigenvalue $=5.632$; accession $\mathrm{x}$ treatment: $F_{8,225}=7.61, P$

$296<0.0001$; ecotype $x$ treatment: $F_{2,225}=6.16, P=0.0025$; Fig. 2 A) and PC3 (Eigenvalue $=3.443$;

297 accession $\mathrm{x}$ treatment: $F_{8,225}=4.03 ; P=0.0002$, ecotype $\mathrm{x}$ treatment: $F_{2,225}=42.07, P<0.0001$; 
298 Fig. 2B). Accession $\mathrm{x}$ treatment and ecotype $\mathrm{x}$ treatment interactions were not significant for

299 PC4 (Table 1).

300

301 Since there were significant ecotype $\mathrm{x}$ treatment interactions for PC2 and PC3, indicating a role

302 of the GA pathway in ecotype divergence, we were interested in which traits might be driving

303 these patterns. Second and third internode length, plant height, total number of stoloniferous

304 nodes sprouting adventitious roots, total number of aerial branches, total number of stolons, and

305 the length of the longest aerial branch all heavily loaded ( $>0.40)$ onto PC2 (Table S2). The total

306 number of aerial branches, the length of the longest aerial branch, number of nodes with

307 adventitious roots, and leaf width heavily loaded onto PC3 (Table S2).

308

309 It should be noted that the effect of GA varied across accessions within ecotype. For example,

310 the coastal PGR accession is the tallest coastal accession with the fewest stolons. This difference

311 in overall morphology likely explains why its response to GA differed from the other four

312 coastal accessions (Fig. S2). The inland perennials showed a similar level of response to GA as

313 the coastal perennials for PC2, but not for PC3 (Fig. 2, S2).

\section{Interactions of $G A$ application with the adaptive DIV1 inversion}

316 Based on a Scree test (Fig. S3), we retained the first three PCs for analyses of the parental

317 genotypes and NILs. Consistent with previous studies (Lowry and Willis 2010; Friedman 2014),

318 the coastal perennial (SWB-S1) and inland annual (LMC-L1) lines were highly divergent in

319 morphological traits and the two lines were differentiated strongly along PC1 $\left(F_{1,163}=314.39, P\right.$

$320<0.0001$; Fig. 3A; Table 2). Similar to the accession analysis (above), the line $\mathrm{x}$ treatment 
321 interaction was not significant for PC1, but was highly significant for PC2 $\left(F_{1,163}=262.49, P<\right.$

322 0.0001; Table 2). The coastal perennial line (SWB-S 1; $N=31$ GA treatment, 42 Mock treatment)

323 responded more strongly (Fig. 3B) to GA treatment for PC2 than the inland annual line (LMC-

$324 \mathrm{~L} 1 ; N=47$ GA treatment, 47 Mock treatment), just as we found across coastal and inland

325 populations more generally (above). The set of traits heavily loading $(>0.40)$ onto PC2 was very

326 similar to that for PC2 of the accession analysis (above): Third internode length, plant height,

327 total number of stoloniferous nodes sprouting adventitious roots, number of adventitious roots at

328 the first node, total number of aerial branches, total number of stolons, and the length of the

329 longest aerial branch (Table S3).

331 The DIV1 chromosomal inversion is one of many loci responsible for divergence between the

332 annual and perennial ecotypes (Hall et al. 2006; Lowry \& Willis 2010; Friedman 2014). Thus,

333 main effects and interactions in the NILs were expected to be subtler than for the parental lines.

334 As in previous studies (Lowry and Willis 2010; Friedman 2014), the inversion had major effects

335 on traits associated with ecotype divergence, with highly significant main effects on PC1 $\left(F_{1,166}\right.$

$336=51.23, P<0.0001$; Table 3$).$ The GA treatment had significant effects on $\mathrm{PCl}\left(F_{1,166}=10.86\right.$,

$337 P=0.0012)$ and PC2 $\left(F_{1,166}=606.48, P<0.0001\right)$. There was a significant, line $\mathrm{x}$ treatment

338 interactions for PC2 $\left(F_{1,166}=24.91, P<0.0001\right.$; Fig. $\left.3 \mathrm{E}\right)$, where Introgression-NILs $(N=39$ GA

339 treatment, 48 Mock treatment) containing perennial inversion orientation responded more to the

340 GA treatment than the Control-NILs $(N=39$ GA treatment, 44 Mock treatment $)$ containing the

341 annual orientation. None of the effects were significant for PC3 after Bonferroni correction for

342 multiple testing (Table 3). 


\section{Effects of the DIVI inversion on resistance compound concentrations}

345 We quantified the concentrations of seven PPGs (Table 4). Consistent with our previous

346 observations (Holeski et al. 2013), the coastal perennial parental (SWB) plants produced 2.5

347 times more total PPGs than the inland annual parental $(\mathrm{LMC})$ plants $\left(F_{1,31}=51.03 ; P<0.0001\right.$;

348 Table 4; Fig. 4). There were also significant differences for six out of seven of the PPGs between

349 the coastal perennial (SWB) and inland annual (LMC) parental lines.

351 Analysis of the DIVI NILs revealed that the introgressed region containing the inversion had

352 major effects on foliar concentrations of PPGs. Control NILs that were homozygous for the

353 coastal orientation of the DIV1 inversion produced 35\% higher concentrations of total PPGs than

354 the introgression NILs, which were homozygous for the inland DIV1 orientation $\left(F_{1,87}=22.70 ; P\right.$

$355<0.0001)$. In addition, the DIV1 locus had significant effects on four out of the seven individual

356 PPGs. Interestingly, the control NILs had higher concentrations of conandroside and

357 mimuloside, but lower concentrations of calceolarioside A and unknown PPG10, than the

358 introgression NILs (Table 4). Thus, the DIV1 inversion influences both the total concentration of

359 PPGs as well as the composition of suites of these PPGs.

\section{DISCUSSION}

362 In this study, we identified a potential mechanism underlying a coordinated evolutionary shift

363 between growth, reproduction, and herbivore resistance in the M. guttatus species complex. Our

364 finding that perennial accessions were more responsive to the GA treatment along the second

365 principal component axis (PC2; Fig. 2B) is consistent with the hypothesis that perennial

366 populations have less GA biosynthesis and/or activity. This pattern was replicated for the coastal 
367 perennial and inland annual parents of the NILs (Fig. 3B). Further, the finding that the

368 introgression NILs had less response to GA addition along the PC2 axis than the control NILs

369 (Fig. 3E) is consistent with the hypothesis that the perennial orientation of the DIVI inversion

370 reduces GA biosynthesis/activity. The morphological traits most likely impacted through this

371 mechanism include plant height, adventitious root production, and whether lateral branches

372 develop as vegetative stolons or upcurved reproductive shoots. Finally, we found that coastal

373 perennial plants and NILs containing the perennial orientation of the inversion produced higher

374 concentration of defensive PPG compound than inland annual plants and NILs containing the

375 inland orientation of the inversion. Therefore, the coastal perennial orientation of the DIVI

376 inversion promotes allocation to long-term growth and herbivore resistance, while the inland

377 orientation promotes allocation of resources to traits associated with rapid reproduction. We

378 discuss these findings in the context of the broader literature below.

Environmental gradients and the evolution of growth, reproduction, and defense traits

381 Studies of intraspecific variation among natural populations adapted to different soil water

382 availability regimes provide an excellent opportunity to understand how the abiotic environment

383 influences the relative allocation of resources by plants to growth and constitutive/induced

384 resistance. Soil water is one of the most limiting factors for plants on Earth (Whittaker 1975;

385 Bohnert et al. 1995; Bray 1997) and can drastically differ in availability among seasons

386 (Cowling et al. 1996), which in turn influences plant resource allocation (Juenger 2013). The

387 timing of soil water availability can dictate the length of the growing season. One major

388 evolutionary strategy for seasonally low water availability is to allocate resources primarily to

389 growth and reproduction to achieve an early flowering, drought escape life-history (Ludlow 
390 1989; Juenger 2013; Kooyers 2015). Beyond selection on plants, soil moisture gradients can

391 drive the abundance of herbivores, which in turn exert their own selective pressures (Kooyers et

392 al. 2017).

393

394 In M. gutattus, evolutionary shifts across a soil moisture gradient drives changes in the allocation

395 not only between growth and reproduction, but also for herbivore resistance (Lowry et al. 2008;

396 Holeski et al. 2013; Kooyers et al. 2017). The phenotypic differences between coastal perennial

397 and inland annual populations is likely driven by multiple selective pressures that are tied to the

398 divergence in soil water availability between coastal and inland habitats. Inland annual habitats

399 generally dry out very quickly at the end of the spring, which leaves little time for a plant to

400 reproduce before being killed by the summer drought. Further, the short growing season may

401 also prevent the establishment of sizable herbivore populations, which would explain the low

402 level of leaf damage in fast drying inland annual habitats (Lowry et al. 2008; Kooyers et al.

403 2017). In contrast, the year-round soil water availability of coastal habitats means that plants

404 growing there have much more time to allocate resources to vegetative growth and herbivore

405 resistance. In addition, wet coastal habitats can build up a considerable load of herbivores, which

406 is likely contribute to the higher incidences of leaf damage and early season mortality at the coast

407 (Lowry et al. 2008; Lowry and Willis 2010; Popovic \& Lowry 2019). For intraspecific

408 differences among populations, the strength of herbivore pressure is thought to be a key driver of

409 plant resistance (Hahn and Maron 2016). It should be noted that a fair amount of leaf damage in

410 coastal habitats may also be due to oceanic salt spray (Boyce 1954; Ahmed and Wainwright

411 1976; Griffiths 2006; Lowry et al. 2009; Popovic \& Lowry 2019). However, a recent 
412 manipulative field experiment did find much greater levels of herbivory of M. guttatus plants in

413 common gardens in coastal habitat than inland habitat (Popovic \& Lowry 2019).

414

415 Our findings in M. guttatus are likely to have implications for intraspecific variation in many

416 other plant species as well. There are many studies that have found similar developmental

417 differences between coastal and inland populations as we have found for M. guttatus (reviewed

418 in Lowry 2012). Given the commonality of coastal plants investing more heavily in lateral

419 vegetative branches versus inland populations investing primarily in upright flowering branches,

420 we predict that coastal population of plants will generally be more highly defended than inland

421 populations, particularly in Mediterranean climates with steep soil water availability gradients.

423 The role of pleiotropy and linkage

424 The results of this study and previous studies (Lowry and Willis 2010; Friedman 2014; Friedman

425 et al. 2015) collectively demonstrate that adaptive chromosomal inversion DIVI contributes to

426 the shift in allocation between long-term growth, short-term fecundity, and herbivore resistance.

427 An outstanding question is whether this coordinated shift is due to genetic linkage or pleiotropy.

428 Chromosomal inversions are thought to evolve as adaptation "supergenes," which can trap

429 multiple linked adaptive loci through their suppression of meiotic recombination (Dobzhansky

430 1970; Kirkpatrick and Barton 2006; Schwander et al. 2014; Wellenreuther and Bernatchez 2018).

431 Thus, the fact that the DIVI inversion contributes to the evolution of multiple phenotypes could

432 be result of adaptive alleles at multiple linked loci being held together in tight linkage by the

433 chromosomal inversion. Alternatively, a single gene within the inversion could have pleiotropic

434 effects on all of the phenotypic changes. Functional studies involving transformation or gene 
435 editing of candidate genes within the inversion will be necessary to distinguish between these

436 alternative hypotheses.

438 Two other recent studies have also found potential pleiotropic effects of genes on allocation to

439 reproduction and herbivore resistance. Rasmann et al. (2018) found that NILs containing genetic

440 variants of the Flowering Locus $C(F L C)$ gene in Cardamine hirsute are responsible for a trade-

441 off between early flowering and herbivore resistance in terms of glucosinolate production.

442 Kerwin et al. (2015) found that there was a positive correlation in Arabidopsis thaliana between

443 glucosinalate production and flowering time for mutant alleles of genes in the glucosinolate

444 biosynthetic pathway. Overall, both of these studies identified the same trade-off of rapid

445 reproduction versus herbivore resistance that we found in our study, although mediated through

446 independent genetic mechanisms.

A hormonal basis of a coordinated shift in the evolution of growth, reproduction, and

449 herbivore resistance?

450 The finding that coastal perennial and inland annual plants respond differentially to GA is

451 consistent with the role of this hormone playing a role in their evolutionary divergence. A recent

452 outlier analysis of coastal perennial and inland annual populations of M. gutattus found that the

453 gene GA20-oxidase2 (GA20ox2) was a major allele frequency outlier between the ecotypes

454 within the vicinity of the DIV1 inversion (Gould et al. 2017). This gene is a strong potential

455 candidate gene for a pleiotropic shift in allocation between growth and reproduction. GA-

456 oxidases are involved in the evolution of dwarfed coastal populations of $A$. thaliana (Barboza et

457 al. 2013) and played a key role in the development of dwarfed Green Revolution rice and barley 
458 (Sasaki et al. 2002; Jia et al. 2009). Further, the DELLA gene, GAI, is located within the vicinity

459 of another growth regulatory QTL (DIV2). GAI was also an allele frequency outlier between

460 coastal and inland populations (Gould et al. 2017). Friedman (2014) found that the DIV1 and

461 DIV2 loci interact epistatically. Thus, it would not be surprising if the genetic changes that

462 underlie both QTL are in the same molecular pathway. Further, the negative antagonism between

463 the GA and JA hormone pathways via the DELLA-JAZ signaling node (Havko et al. 2016; Guo

464 et al. 2018; Howe et al. 2018) suggests a direct mechanism by which trade-offs between growth,

465 reproduction, and resistance could easily evolve. Future functional genetic studies will be needed

466 to determine whether these genes in fact are involved in adaptive shifts between growth,

467 reproduction, and defense underlying local adaptation in this system.

469 While we saw a greater response to GA addition in coastal plants and observed an interaction

470 between GA addition and the inversion, other hormones could also play a role or even be the

471 ultimate cause of the divergence between the coastal perennial and inland annual ecotypes. Three

472 major classes of hormones, Auxins, Brassinosteroids and Gibberellins, are all associated with

473 growth phenotypes like those that differ between coastal perennial and inland annual ecotypes of

474 M. guttatus (Ross and Quittenden 2016; Unterholzner et al. 2016). These hormones interact in

475 multiple ways, which have yet to be fully elucidated, to result in shifts in growth/reproduction 476 phenotypes.

\section{Conclusions and future directions}

479 There are numerous evolutionary and ecological models that make predictions on the evolution

480 of relationships between growth, reproduction, and herbivore resistance. While recent meta- 
481 analyses have found that some models have moderate support (Endara and Coley 2011), there

482 are many exceptions and some models appear to not be well supported at all (Stamps et al. 2003;

483 Hahn and Maron 2016; Smilanich et al. 2016). The reasons that these models do not hold up are

484 often attributed to vast variation in the extrinsic environmental factors that exert selective

485 pressures on plant populations, broad variation in life-history among plant species, differences

486 between interspecific and intraspecific variation, and variation in herbivore abundances across

487 environmental gradients (Stamps et al. 2003; Hahn and Maron 2016; Smilanich et al. 2016; Hahn

488 et al. 2019). Less well appreciated are the molecular genetic mechanisms that underlie shifts in

489 allocation between growth, reproduction, and herbivore resistance (Kerwin et al. 2015; Rasmann

490 et al. 2018). The nature of the gene networks responsible for shifts in allocation may also be very

491 important for whether or not particular systems will conform to a given evolutionary or

492 ecological model. Future research should focus on uncovering the molecular mechanisms that

493 underlie the evolution of growth, reproduction, and defense trade-offs in natural populations and

494 integrate predictions from those mechanisms into ecological and evolutionary models.

\section{LITERATURE CITED}

497 Agrawal, A. A., J. K. Conner, and S. Rasmann. 2010. Tradeoffs and adaptive negative

498 correlations in evolutionary ecology. Pp. 243-268 in M. A. Bell, et al., eds. Evolution after

499 Darwin: The first 150 years. Sinaur Press, Sunderland, MA.

501 Agren, J., and D. W. Schemske. 1993. The cost of defense against herbivores: an experimental

502 study of trichome production in Brassica rapa. Am. Nat. 141:338-350. 
504 Ahmad, I., and S. E. Wainwright. 1976. Ecotype differences in leaf surface properties of Agrostis

505 stolonifera from salt marsh, spray zone and inland habitats. New Phytol. 76:361-366.

506

507 Baker, R. L., and P. K. Diggle. 2011. Node-specific branching and heterochronic changes

508 underlie population-level differences in Mimulus guttatus (Phrymaceae) shoot architecture. Am.

509 J. Bot. 98:1924-1934.

510

511 Baker, R. L., L. C. Hileman, and P. K. Diggle. 2012. Patterns of shoot architecture in locally

512 adapted populations are linked to intraspecific differences in gene regulation. New Phytol.

513 196:271-281.

514

515 Barboza, L., S. Effgen, C. Alonso-Blanco, R. Kooke, J. J B. Keurentjes, M. Koornneef, and R.

516 Alcázar. 2013. Arabidopsis semidwarfs evolved from independent mutations in GA20ox1,

517 ortholog to green revolution dwarf alleles in rice and barley. Proc. Natl. Acad. Sci. 201314979.

519 Bohnert, H. J., Nelson D. E., and Jensen R. G. 1995. Adaptations to environmental stresses. Plant $520 \quad$ Cell 7:1099-1111.

522 Boyce, S. G. 1954. The salt spray community. Ecol. Monograph. 24:29-67.

524 Bray, E. A. 1997. Plant responses to water deficit. Trends Plant Sci. 2:48-54. 
526 Campos, M. L., Y. Yoshida, I. T. Major, D. de Oliveira Ferreira, S. M. Weraduwage, J. E.

527 Froehlich, B. F. Johnson, D. M. Kramer, G. Jander, T. D. Sharkey, and G. A. Howe. 2016.

528 Rewiring of jasmonate and phytochrome B signalling uncouples plant growth-defense tradeoffs.

529 Nat. Commun. 7:12570.

530

531 Cipollini, D., D. Walters, C. Voelckel. 2014. Costs of resistance in plants: from theory to

532 evidence. Annu. Plant Rev. 47:263-307.

534 Clausen, J., and W. H. Hiesey. 1958. Experimental studies on the nature of species. IV. Genetic 535 structure of ecological races. Carnegie Institution of Washington, Washington, DC.

537 Coley, P. D., J. P Bryant, F. F. S. Chapin III. 1985. Resource availability and plant antiherbivore 538 defense. Science 230:895-899.

540 Cowling, R. M., P. W Rundel., B. B. Lamont, M. K. Arroyo, and M. Arianoutsou. 1996. Plant

541 diversity in Mediterranean-climate regions. Trends Ecol. Evol. 11:362-366.

543 Defossez, E., L. Pellissier, and S. Rasmann. 2018. The unfolding of plant growth form-defense 544 syndromes along elevational gradients. Ecol. Lett. 21:609-618.

546 Dobzhansky, T. 1970. Genetics of the Evolutionary Process. Columbia University Press, New 547 York, NY. 
549 Endara, M. J., and P. D. Coley. 2011. The resource availability hypothesis revisited: A meta-

550 analysis. Funct. Ecol. 25:389-398.

551

552 Feeny, P. 1976 Plant apparency and chemical defense. Pp. 1-40 in J. W. Wallace and R. L.

553 Mansell, eds. Biochemical interaction between plants and insects. Springer, Boston, MA.

555 Ferris, K. G., L. L. Barnett, B. K. Blackman, J. H. Willis. 2017. The genetic architecture of local

556 adaptation and reproductive isolation in sympatry within the Mimulus guttatus species complex.

557 Mol. Ecol. 26:208-224.

559 Fine, P. V, Z. J. Miller, I. Mesones, S. Irazuzta, H. M. Appel, M. H. Stevens, I. Sääksjärvi, J. C.

560 Schultz, and P. D. Coley. 2006. The growth-defense trade-off and habitat specialization by

561 plants in Amazonian forests. Ecology 87:S150-S162.

562

563 Forister, M. L., L. A. Dyer, M. S. Singer, J. O. Stireman, and J. T. Lill. 2012. Revisiting the

564 evolution of ecological specialization, with emphasis on insect-plant interactions. Ecology

565 93:981-991.

566

567 Friedman, J. 2014. Genetic determinants and epistasis for life history trait differences in the 568 common monkeyflower, Mimulus guttatus. J. Heredity 105:910-921. 
570 Friedman, J., and J. H. Willis. 2013. Major QTLs for critical photoperiod and vernalization

571 underlie extensive variation in flowering in the Mimulus guttatus species complex. New Phytol.

572 199:571-583.

573

574 Friedman, J., A. D. Twyford, J. H. Willis, and B. K. Blackman. 2015. The extent and genetic

575 basis of phenotypic divergence in life history traits in Mimulus guttatus. Mol. Ecol. 24:111-122.

576

577 Friedman, J., and M. J. Rubin. 2015. All in good time: understanding annual and perennial

578 strategies in plants. American Journal of Botany 102:497-499.

580 Futuyma, D. J., and G. Moreno. 1988. The evolution of ecological specialization. Annu. Rev.

$581 \quad$ Ecol. Syst. 19:207-233.

583 Gould, B. A., Y. Chen, and D. B. Lowry. 2017. Pooled ecotype sequencing reveals candidate

584 genetic mechanisms for adaptive differentiation and reproductive isolation. Mol. Ecol. 26:163585177.

587 Griffiths, M.E., and C. M. Orians. 2003. Salt spray differentially affects water status, necrosis, 588 and growth in coastal sandplain heathland species. Am. J. Bot. 90:1188-1196.

590 Hahn, P. G., and J. L. Maron. 2016. A framework for predicting intraspecific variation in plant 591 defense. Trends Ecol. Evol. 31:646-656. 
593 Hahn, P. G., Agrawal, A. A., Sussman, K. I., and J. L. Maron. 2019. Population variation,

594 environmental gradients, and the evolutionary ecology of plant defense against herbivory. Am.

595 Nat. 193:20-34.

596

597 Hall, M. C., and J. H. Willis. 2006. Divergent selection on flowering time contributes to local

598 adaptation in Mimulus guttatus populations. Evolution 60:2466-2477.

599

600 Hall, M. C., D. B. Lowry, and J. H. Willis. 2010. Is local adaptation in Mimulus guttatus caused

601 by trade-offs at individual loci? Mol. Ecol. 19:2739-2753.

602

603 Hamilton, J. G., A. R. Zangerl, E. H. DeLucia, and M. R. Berenbaum. 2001. The carbon-nutrient

604 balance hypothesis: its rise and fall. Ecol. Lett. 4:86-95.

605

606 Havko, N. E., I. T. Major, J. B. Jewell, E. Attaran, and G. A. Howe. 2016. Control of carbon

607 assimilation and partitioning by jasmonate: An accounting of growth-defense tradeoffs. Plants

$608 \quad 5: 7$.

609

610 Heil, M., and I. T. Baldwin. 2002. Fitness costs of induced resistance: emerging experimental

611 support for a slippery concept. Trends Plant Sci. 7:61-67.

612

613 Hereford, J. 2009. A quantitative survey of local adaptation and fitness trade-offs. Am. Nat.

$614 \quad$ 173:579-588.

615 
616 Herms, D. A., and W. J. Mattson. 1992. The dilemma of plants: to grow or defend. Q. Rev. Biol.

$617 \quad 67: 283-335$

618

619 Holeski, L. M., K. Keefover-Ring, M. D. Bowers, Z. T. Harnenz, and R. L. Lindroth. 2013.

620 Patterns of phytochemical variation in Mimulus guttatus (yellow monkeyflower). J. Chem. Ecol.

$621 \quad 39: 525-536$.

622

623 Holeski, L. M., P. Monnahan, B. Koseva, N. McCool, R. L. Lindroth, and J. K. Kelly. 2014. A

624 high-resolution genetic map of yellow monkeyflower identifies chemical defense QTLs and

625 recombination rate variation. Genes Genom. Genet. 4:813-821.

626

627 Huot, B., J. Yao, B. L. Montgomery, and S. Y. He. 2014. Growth-defense tradeoffs in plants: a

628 balancing act to optimize fitness. Mol. Plant. 7:1267-1287.

629

630 Howe, G. A., I. T. Major, and A. J. Koo. 2018. Modularity in jasmonate signaling for multistress

631 resilience. Annu. Rev. Plant Biol. 69:387-415.

632

633 Hou, X., L. Ding, and H. Yu. 2013. Crosstalk between GA and JA signaling mediates plant

634 growth and defense. Plant Cell Rep. 32:1067-1074.

635

636 Jensen, L.M., H. K. Jepsen, B. A. Halkier, D. J. Kliebenstein, and M. Burow. 2015 Natural

637 variation in cross-talk between glucosinolates and onset of flowering in Arabidopsis. Front. Plant

638 Sci. 6:697. 
640 Jia, Q., J. Zhang, S. Westcott, X-Q. Zhang, M. Bellgard, R. Lance, C. Li. 2009. GA-20 oxidase

641 as a candidate for the semidwarf gene sdw1/denso in barley. Funct. Integr. Genomics. 9:255-262

642

643 Juenger, T. E. 2013 Natural variation and genetic constraints on drought tolerance. Curr. Opin.

644 Plant Biol. 16:274-281.

645

646 Karban, R. 2011. The ecology and evolution of induced resistance against herbivores. Funct.

647 Ecol. 25:339-347.

648

649 Kazan, K., and J. M. Manners. 2012. JAZ repressors and the orchestration of phytohormone 650 crosstalk. Trends Plant Sci. 17:22-31.

652 Kawecki, T. J. 1988. Red queen meets Santa Rosalia: arms races and the evolution of host 653 specialization in organisms with parasitic lifestyles. Am. Nat. 152:635-651.

655 Kawecki, T. J., and Ebert D. 2004. Conceptual issues in local adaptation. Ecol. Lett. 7:1225-

6561241.

657

658 Kerwin, R., J. Feusier, J. Corwin, M. Rubin, C. Lin, A. Muok, B. Larson, B. Li, B. Joseph, M.

659 Francisco, and D. Copeland. 2015. Natural genetic variation in Arabidopsis thaliana defense

660 metabolism genes modulates field fitness. eLife. 4:e05604. 
662 Kirkpatrick, M., and N. H. Barton. 2006. Chromosome inversions, local adaptation and

663 speciation. Genetics 173:419-434.

664

665 Kooyers, N. J. 2015. The evolution of drought escape and avoidance in natural herbaceous

666 populations. Plant Sci. 234:155-162.

667

668 Kooyers, N. J., B. K. Blackman, and L. M. Holeski. 2017 Optimal defense theory explains

669 deviations from latitudinal herbivory defense hypothesis. Ecology 98:1036-1048.

670

671 Lowry, D. B., R. C. Rockwood, and J. H. Willis. 2008. Ecological reproductive isolation of coast

672 and inland races of Mimulus guttatus. Evolution 62:2196-2214.

673

674 Lowry, D. B., M. C. Hall, D. E. Salt, and J. H. Willis. 2009. Genetic and physiological basis of

675 adaptive salt tolerance divergence between coastal and inland Mimulus guttatus. New Phytol.

$676 \quad$ 183:776-788.

677

678 Lowry, D. B., and J. H. Willis. 2010. A widespread chromosomal inversion polymorphism

679 contributes to a major life-history transition, local adaptation, and reproductive isolation. PLoS

680 Biol. 8:e1000500.

681

682 Lowry, D. B. 2012. Ecotypes and the controversy over stages in the formation of new species.

683 Biol. J. Linnean Soc. 106:241-257. 
685 Ludlow, M. M. 1989. Strategies of response to water stress. Pp. 509-519 in K. H. Kreeb et al.

686 (Eds.), Structural and functional responses to environmental stresses. SPB Academic, The

687 Hague.

688

689 Lorenzo, O., J. M. Chico, J. J. Sanchez-Serrano, and R. Solano. 2004. JASMONATE-

690 INSENSITIVE1 encodes a MYC transcription factor essential to discriminate between different

691 jasmonate-regulated defense responses in Arabidopsis. Plant Cell 16:1938-1950.

692

693 Major, I. T., Y. Yoshida, M. L. Campos, G. Kapali, X. F. Xin, K. Sugimoto, D. Oliveira Ferreira,

694 S. Y. He, and G. A. Howe. 2017. Regulation of growth-defense balance by the JASMONATE

695 ZIM-DOMAIN (JAZ)-MYC transcriptional module. New Phytol. 215:1533-1547.

697 Mason, C. M., and L. A. Donovan. 2015. Evolution of the leaf economics spectrum in herbs:

698 evidence from environmental divergences in leaf physiology across Helianthus (Asteraceae).

699 Evolution 69:2705-2720.

700

701 Moreira, X., R. Zas, A. Solla, and L. Sampedro. 2015. Differentiation of persistent anatomical

702 defensive structures is costly and determined by nutrient availability and genetic growth-defence

703 constraints. Tree Physiol. 35:112-123.

704

705 Oneal, E., D. B. Lowry, K. M. Wright, Z. Zhu, and J. H. Willis. 2014. Divergent population

706 structure and climate associations of a chromosomal inversion polymorphism across the Mimulus

707 guttatus species complex. Mol. Ecol. 23:2844-2860. 
709 Popovic, D., and D. B. Lowry. 2019. Oceanic salt spray and herbivore pressure contribute to

710 local adaptation of coastal perennial and inland annual ecotypes of the Seep Monkeyflower

711 (Mimulus guttatus). BioRxiv. 523902.

712

713 Rasmann, S., J. Sánchez Vilas, G. Glauser, M. Cartolano, J. Lempe, M. Tsiantis, and J. R.

714 Pannell. 2018. Pleiotropic effect of the Flowering Locus C on plant resistance and defence

715 against insect herbivores. J. Ecol. 106:1244-1255.

716

717 Rausher, M. D. 1996. Genetic analysis of coevolution between plants and their natural enemies.

718 Trends in Genetics 12:212-217.

719

720 Rhoades, D. F. 1979. Evolution of plant chemical defense against herbivores. P.p. 3-54 in G. A.

721 Rosenthal and D. H. Janzen, editors. Herbivores: their interaction with secondary plant

722 metabolites. Academic Press, Orlando, Florida, USA.

723

724 Ross J. J., and L. J. Quittenden. 2016. Interactions between brassinosteroids and gibberellins:

725 Synthesis or Signaling? Plant Cell 28:829-832.

727 Rotter, M. C., J. J. Couture, E. M. Rothwell, J. Garcia, and L. M. Holeski. 2018. Evolutionary

728 ecology of plant resistance traits across the herbivore diet spectrum: A test in the model plant

729 Mimulus guttatus. Evolutionary Ecology Research 19:423-440. 
731 Sasaki A., M. Ashikari, M. Ueguchi-Tanaka, H. Itoh, A. Nishimura, D. Swapan, K. Ishiyama, T.

732 Saito, M. Kobayashi, G. S. Khush, H. Kitano, and M. Matsuoka 2002. Green revolution: a

733 mutant gibberellin-synthesis gene in rice. Nature 416:701.

734

735 Schwander, T., R. Libbrecht, and L. Keller. 2014. Supergenes and complex phenotypes. Curr.

736 Biol. 24:R288-R294.

737

738 Smilanich, A. M., R. M. Fincher, and L. A. Dyer. 2016. Does plant apparency matter? Thirty

739 years of data provide limited support but reveal clear patterns of the effects of plant chemistry on

740 herbivores. New Phytol. 210:1044-1057.

742 Stamp, N. 2003 Out of the quagmire of plant defense hypotheses. Q. Rev. Biol. 78:23-55.

744 Strauss, S.Y., J.A. Rudgers, J.A. Lau, and R.E. Irwin. 2002. Direct and ecological costs of

745 resistance to herbivory. Trends Ecol. Evol. 17:278-285.

747 Stowe, K. A., and R. J. Marquis. 2011. Costs of defense: correlated responses to divergent

748 selection for foliar glucosinolate content in Brassica rapa. Evol. Ecol. 25:763-775.

750 Svanbäck, R., and P. Eklöv. 2003. Morphology dependent foraging efficiency in perch: a trade-

751 off for ecological specialization? Oikos 102:273-284. 
753 Twyford, A. D., and J. Friedman. 2015. Adaptive divergence in the monkey flower Mimulus

754 guttatus is maintained by a chromosomal inversion. Evolution 69:1476-1486.

755

756 Uesugi, A., T. Connallon, A. Kessler, and K. Monro, 2018. Relaxation of herbivore-mediated

757 selection drives the evolution of genetic covariances between plant competitive and defense

758 traits. Evolution 71:1700-1709.

759

760 Unterholzner, S. J., W. Rozhon, and B. Poppenberger. 2016. Reply: Interaction between

761 Brassinosteroids and Gibberellins: Synthesis or Signaling? In Arabidopsis, Both! Plant Cell.

$762 \quad 28: 836-839$.

763

764 van Dam, N. M., and I. T. Baldwin. 1998. Costs of jasmonate-induced responses in plants

765 competing for limited resources. Ecol. Lett. 1:30-33.

766

767 Wellenreuther, M., and L. Bernatchez. 2018. Eco-evolutionary genomics of chromosomal

768 inversions. Trends Ecol. Evol. 33:427-440.

769

770 Whitlock, M. C. 1996. The red queen beats the jack-of-all-trades: the limitations on the evolution

771 of phenotypic plasticity and niche breadth. Am. Nat. 148:S65-S77.

772

773 Whittaker, R. H. 1975. Communities and Ecosystems. McMillan, New York, NY. 
775 Yan, Y., S. Stolz, A. Chetelat, P. Reymond, M. Pagni, L. Dubugnon, and E. E. Farmer. 2007. A

776 downstream mediator in the growth repression limb of the jasmonate pathway. Plant Cell

$777 \quad$ 19:2470-2483.

778

779 Yang, D. L., J. Yao, C. S. Mei, X. H. Tong, L. J. Zeng, Q. Li, L. T. Xiao, T. P. Sun, J. Li, X. W.

780 Deng, C. M. Lee, M. F. Thomashow, Y. Yang, Z. He, S. Y. He. 2012. Plant hormone jasmonate

781 prioritizes defense over growth by interfering with gibberellin signaling cascade. Proc. Nat.

$782 \quad$ Acad. Sci. 109:E1192-1200.

783

784 Zhang, Y., and J. Turner. 2008. Wound-induced endogenous jasmonates stunt plant growth by

785 inhibiting mitosis. PLoS ONE 3:e3699.

786

787

788

789

790

791

792

793

794

795

796

797 
TABLES

799 Table 1. Effects of individual factors and their interactions on the first four principal components

800 of 37 morphological traits quantified in the experiment comparing ecotypes and accessions.

\begin{tabular}{llrrrr}
\hline Trait & Source & DF & \multicolumn{1}{c}{ SS } & \multicolumn{1}{c}{ F } & P \\
\hline PC1 & Accession[Ecotype] & 8 & 730.32 & 23.70 & $<0.0001^{*}$ \\
PC1 & Ecotype & 2 & 1626.14 & 211.04 & $<0.0001^{*}$ \\
PC1 & Treatment & 1 & 58.63 & 15.22 & $0.0001^{*}$ \\
PC1 & Accession*Treatment[Ecotype] & 8 & 79.71 & 2.59 & $0.0101^{*}$ \\
PC1 & Ecotype*Treatment & 2 & 12.77 & 1.66 & 0.1930 \\
PC2 & Accession[Ecotype] & 8 & 366.72 & 20.82 & $<0.0001^{*}$ \\
PC2 & Ecotype & 2 & 54.38 & 12.35 & $<0.0001^{*}$ \\
PC2 & Treatment & 1 & 173.77 & 78.92 & $<0.0001^{*}$ \\
PC2 & Accession*Treatment[Ecotype] & 8 & 134.09 & 7.61 & $<0.0001^{*}$ \\
PC2 & Ecotype*Treatment & 2 & 27.12 & 6.16 & $0.0025^{*}$ \\
PC3 & Accession[Ecotype] & 8 & 169.98 & 14.15 & $<0.0001^{*}$ \\
PC3 & Ecotype & 2 & 5.76 & 1.92 & 0.1492 \\
PC3 & Treatment & 1 & 51.18 & 34.08 & $<0.0001^{*}$ \\
PC3 & Accession*Treatment[Ecotype] & 8 & 48.37 & 4.03 & $0.0002^{*}$ \\
PC3 & Ecotype*Treatment & 2 & 126.35 & 42.07 & $<0.0001^{*}$ \\
PC4 & Accession[Ecotype] & 8 & 143.39 & 16.28 & $<0.0001^{*}$ \\
PC4 & Ecotype & 2 & 109.37 & 49.66 & $<0.0001^{*}$ \\
PC4 & Treatment & 1 & 0.51 & 0.46 & 0.4981 \\
PC4 & Accession*Treatment[Ecotype] & 8 & 15.28 & 1.73 & 0.0916 \\
PC4 & Ecotype*Treatment & 2 & 0.42 & 0.19 & 0.8247 \\
\hline & & & & &
\end{tabular}

*Significant after Bonferroni correction for multiple testing $(P<0.0125)$ 
809 Table 2. Effects of line (SWB-S1 vs. LMC-L1), treatment (GA vs. Mock), and the interaction on

810 the first three principal of 37 morphological traits quantified for the parental inbred lines.

\begin{tabular}{llrrr}
\hline Trait & Source & \multicolumn{1}{l}{ SS } & \multicolumn{1}{c}{ F } & \multicolumn{1}{c}{ P } \\
\hline PC1 & Line & 2027.14 & 314.39 & $<0.0001^{*}$ \\
PC1 & Treatment & 145.75 & 22.6 & $<0.0001^{*}$ \\
PC1 & Line*Treatment & 7.06 & 1.10 & 0.2969 \\
PC2 & Line & 42.25 & 15.61 & $0.0001^{*}$ \\
PC2 & Treatment & 257.86 & 95.24 & $<0.0001^{*}$ \\
PC2 & Line*Treatment & 262.49 & 96.95 & $<0.0001^{*}$ \\
PC3 & Line & 2.12 & 0.63 & 0.4271 \\
PC3 & Treatment & 32.51 & 9.74 & $0.0021^{*}$ \\
PC3 & Line*Treatment & 15.73 & 4.71 & 0.0314 \\
\hline
\end{tabular}

811

*Significant after Bonferroni correction for multiple testing $(P<0.0083)$

812 Table 3. Effects of line (Introgression-NIL vs. Control-NIL), treatment (GA vs. Mock), and the

813 interaction on the first three principal of 37 morphological traits quantified for the parental

814 inbred lines.

\begin{tabular}{llrrr}
\hline Trait & Source & \multicolumn{1}{c}{ SS } & \multicolumn{1}{c}{ F } & \multicolumn{1}{c}{ P } \\
\hline PC1 & Line & 206.86 & 51.23 & $<0.0001^{*}$ \\
PC1 & Treatment & 43.84 & 10.86 & $0.0012^{*}$ \\
PC1 & Line*Treatment & 28.17 & 6.98 & 0.0090 \\
PC2 & Line & 0.02 & 0.01 & 0.9072 \\
PC2 & Treatment & 606.48 & 389.98 & $<0.0001^{*}$ \\
PC2 & Line*Treatment & 24.91 & 16.02 & $<0.0001^{*}$ \\
PC3 & Line & 21.12 & 5.50 & 0.0202 \\
PC3 & Treatment & 3.90 & 1.02 & 0.315 \\
PC3 & Line*Treatment & 10.15 & 2.64 & 0.1059 \\
\hline
\end{tabular}

815

*Significant after Bonferroni correction for multiple testing $(P<0.0083)$ 
817 Table 4. Means (standard errors) and Tukey HSD post-hoc results for the concentrations of

818 phenylpropanoid glycosides in coastal perennial (SWB) and inland annual (LMC) parents as well

819 as near-isogenic lines of the DIV1 inversion in the coastal perennial genetic background.

\begin{tabular}{lrrrr}
\hline Trait & Coastal Parent $(\boldsymbol{N}=\mathbf{2 5})$ & Inland Parent $(\boldsymbol{N}=\mathbf{8})$ & Control NIL $(\boldsymbol{N = 5 4})$ & Introgression NIL $(\boldsymbol{N}=\mathbf{3 5})$ \\
\hline Total PPGs & $164.24(7.74) \mathrm{A}$ & $65.65(13.69) \mathrm{C}$ & $161.32(5.27) \mathrm{A}$ & $119.67(6.55) \mathrm{B}$ \\
Conandroside & $105.11(6.65) \mathrm{A}$ & $42.26(11.75) \mathrm{B}$ & $106.98(4.52) \mathrm{A}$ & $55.71(5.62) \mathrm{B}$ \\
Calceolarioside A & $37.15(2.13) \mathrm{B}$ & $12.79(3.77) \mathrm{C}$ & $32.77(1.45) \mathrm{B}$ & $46.30(1.80) \mathrm{A}$ \\
Mimuloside & $7.93(0.64) \mathrm{A}$ & $3.62(1.13) \mathrm{B}$ & $7.54(0.43) \mathrm{A}$ & $4.24(0.55) \mathrm{B}$ \\
Verbascoside & $6.91(0.36) \mathrm{A}$ & $1.90(0.63) \mathrm{B}$ & $6.89(0.24) \mathrm{A}$ & $5.90(0.30) \mathrm{A}$ \\
Calceolarioside B & $0.98(0.08) \mathrm{A}$ & $0.33(0.13) \mathrm{B}$ & $0.66(0.06) \mathrm{B}$ & $0.62(0.06) \mathrm{B}$ \\
Unknown PPG 16 & $5.52(0.44) \mathrm{A}$ & $4.56(0.77) \mathrm{A}$ & $5.87(0.30) \mathrm{A}$ & $6.09(0.37) \mathrm{A}$ \\
Unknown PPG10 & $0.64(0.04) \mathrm{B}$ & $0.19(0.07) \mathrm{C}$ & $0.60(0.03) \mathrm{B}$ & $0.81(0.03) \mathrm{A}$ \\
\hline
\end{tabular}

Mean (SE) and Tukey HSD post-hoc results. Sample sizes in parentheses.

\section{FIGURE LEGENDS}

824 Figure 1. A) Map of coastal perennial (blue), inland annual (yellow), and inland perennial

825 (green) populations from where accessions for experiment were derived. B) Effects of the

826 introgression of the inland DIVI inversion orientation into the coastal perennial genetic

827 background. Left: Coastal perennial parental inbred line. Center: Control Near Isogenic Line

828 (NIL) containing the coastal orientation of the inversion. Right: Introgression NIL containing the

829 inland orientation of the inversion. All three plants germinated on the same day. C) Differential

830 responses of inland annual and coastal perennial accessions to gibberellin treatment and water

831 control (mock).

832

833 Figure 2. Least square means of ecotype $\mathrm{x}$ treatment interactions of the first four principal

834 components for coastal perennial, inland annual, and inland perennial ecotypes in response to

835 mock and gibberellin treatments. Error bars are standard errors. 
837 Figure 3. Least square means of line $\mathrm{x}$ treatment interactions of coastal perennial (SWB-S1) and

838 inland annual (LMC-L1) parents and coastal perennial genetic background near-isogenic lines

839 (NILs) to mock and gibberellin treatments. The introgression NILs were homozygous for the

840 inland annual orientation of the DIV1 inversion, while the control NILs were homozygous for the

841 coastal perennial orientation of the DIVI inversion. Lower case letters indicate significant

842 differences of least square means by Tukey HSD post hoc analyses. Error bars are standard

843 errors.

844

845 Figure 4. Concentration of phenylpropanoid glycosides for coastal perennial (SWB-S2xS3) and

846 inland annual (LMC-L2xL3) parents as well as coastal perennial genetic background near-

847 isogenic lines (NILs). The introgression NILs were homozygous for the inland annual orientation

848 of the DIV1 inversion, while the control NILs were homozygous for the coastal perennial

849 orientation of the DIV1 inversion.

\section{Supplemental Materials}

853 Table S1. Collection locations of population accessions used in this study, including the number

854 of individuals used for ANOVAs of principal components per each accession.

856 Table S2. Trait loadings on the first four principle components axes for experiment comparing

857 population accession. Percent of variation explained by each PC included in parentheses. 
859 Table S3. Trait loadings on the first three principle components axes for all plants grown in the

860 experiment with near isogenic lines and the parental genotypes. Percent of variation explained by

861 each PC included in parentheses.

862

863 Figure S1. Scree plot of eigenvalues for principal components analysis of trait data collected for

864 population accessions

865

866 Figure S2. Least square means of accession $x$ treatment interactions of the first four principal

867 components for coastal perennial, inland annual, and inland perennial accessions in response to

868 mock and gibberellin treatments.

869

870 Figure S3. Scree plot of eigenvalues for principal components analysis of trait data collected for

871 experiment with near isogenic lines and parental lines. 

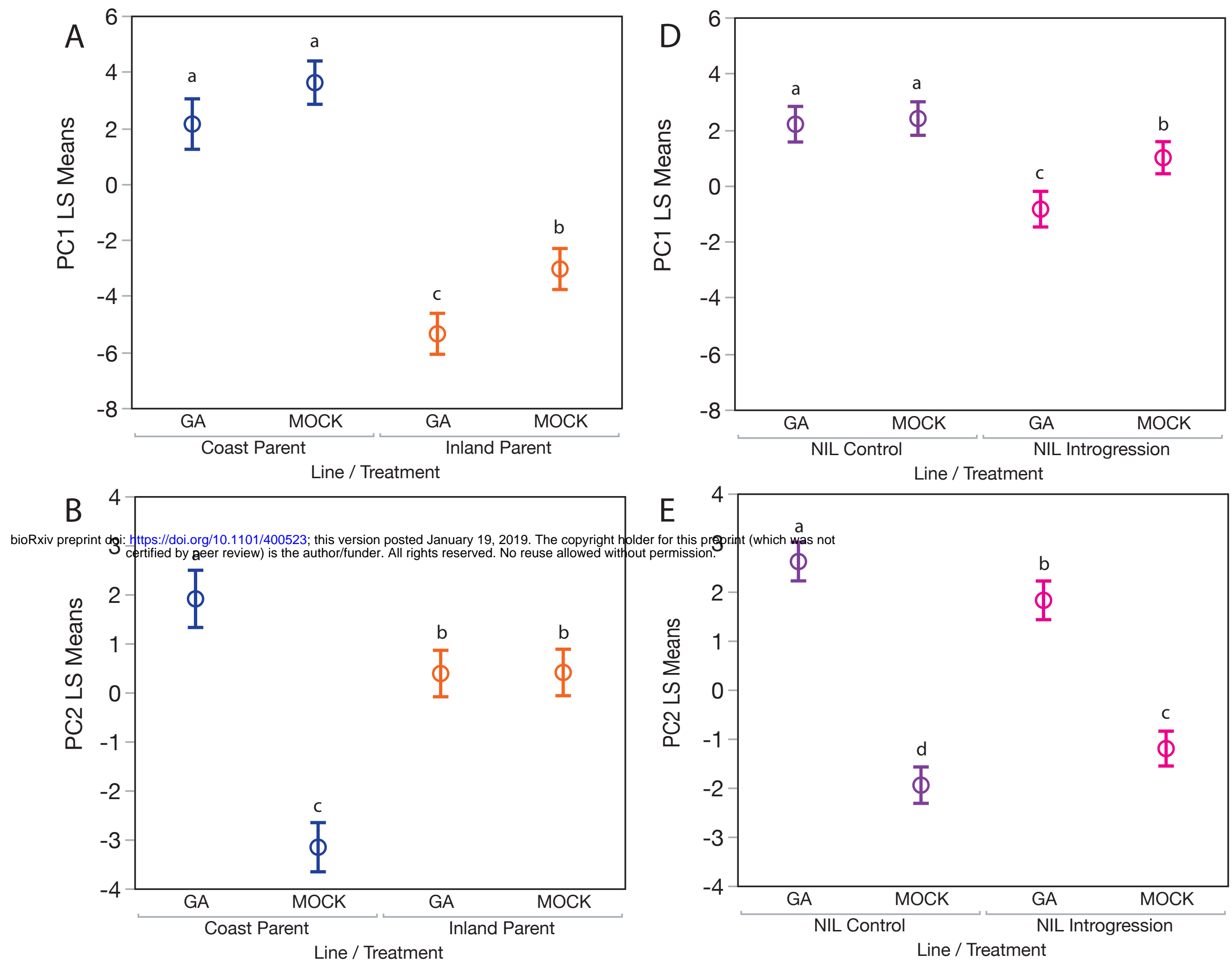

E
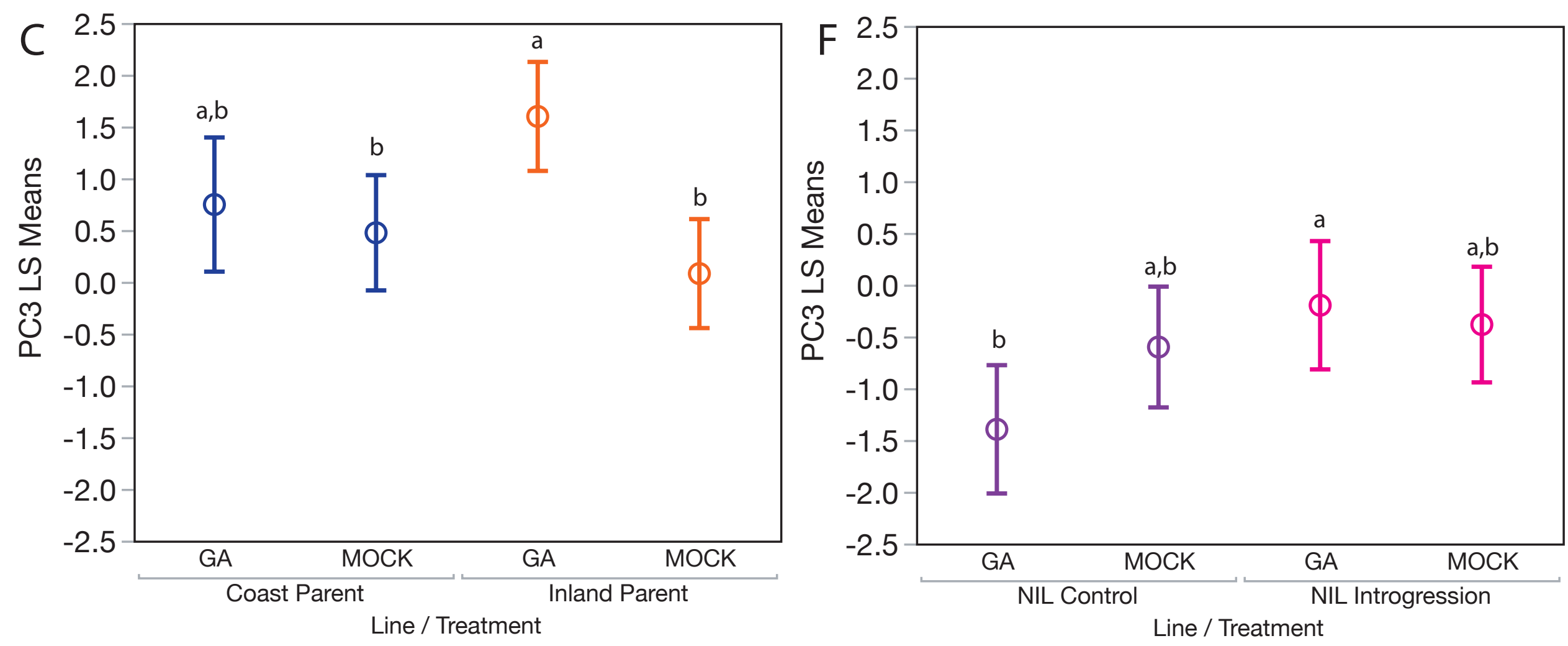


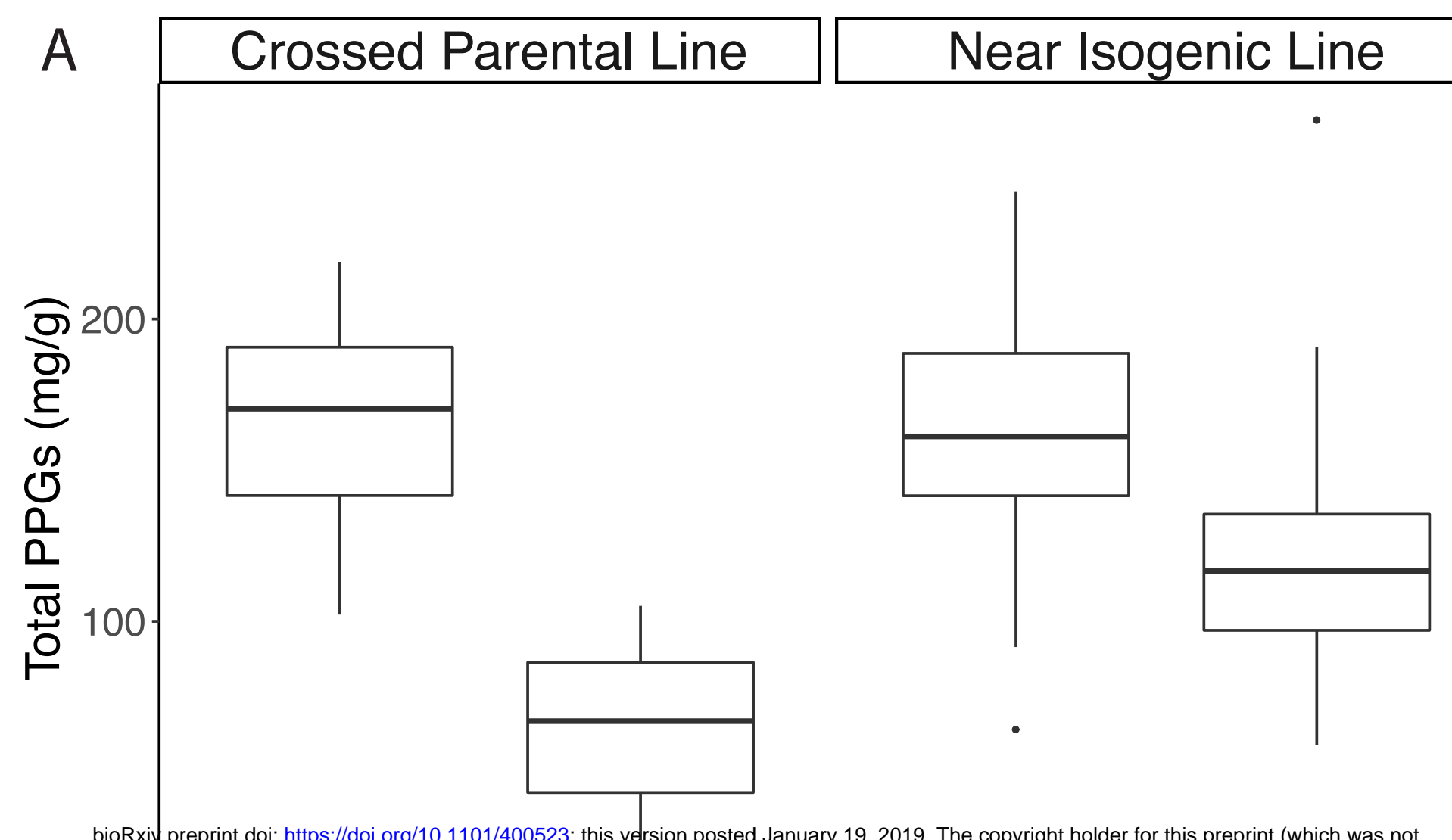

certified by peer review) is the author/funder. All rights reserved. No reuse allowed without permission.

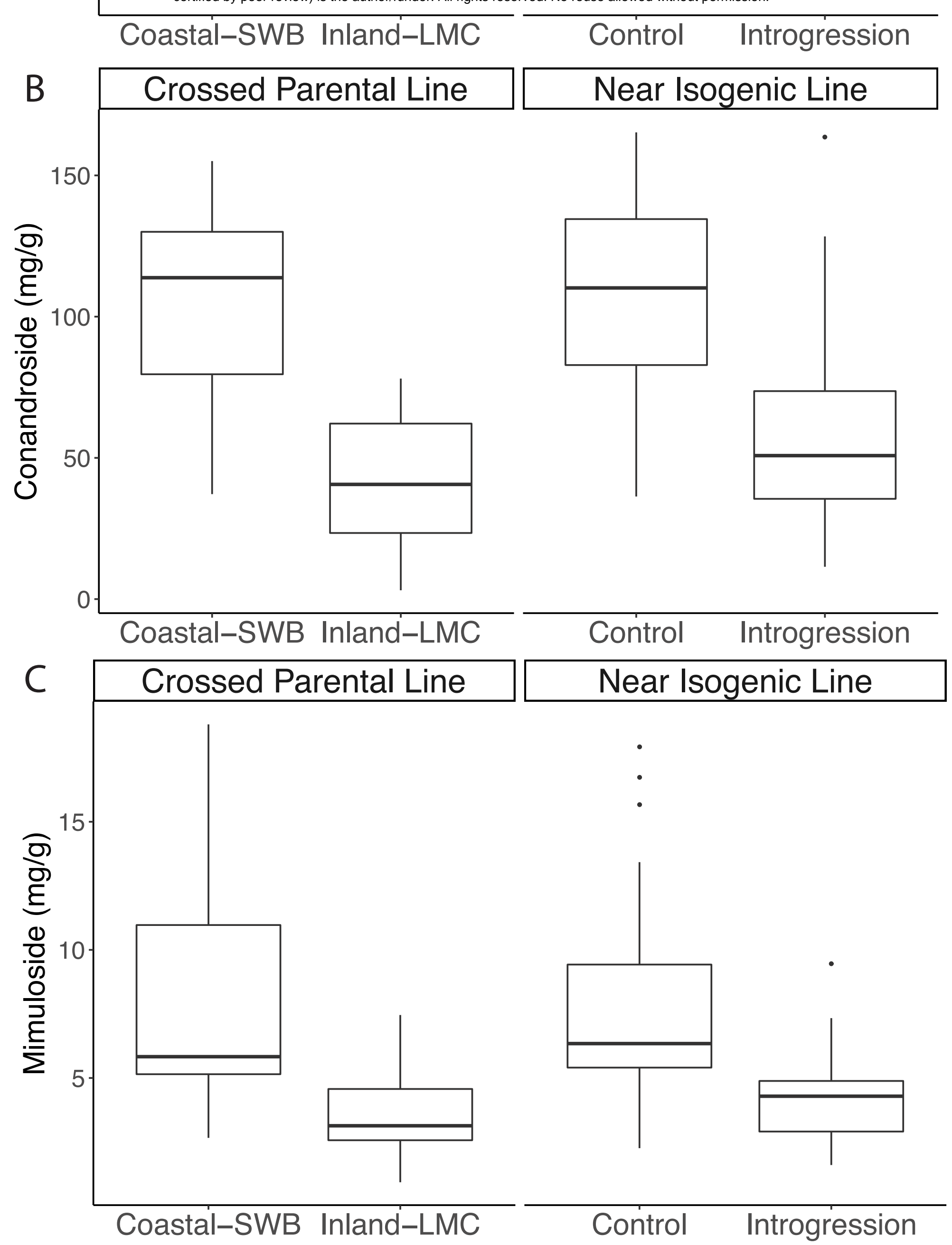


bioRxiv preprint doi: https://doi.org/10.1101/400523; this version posted January 19, 2019. The copyright holder for this preprint (which was not certified by peer review) is the author/funder. All rights reserved. No reuse allowed without permission.

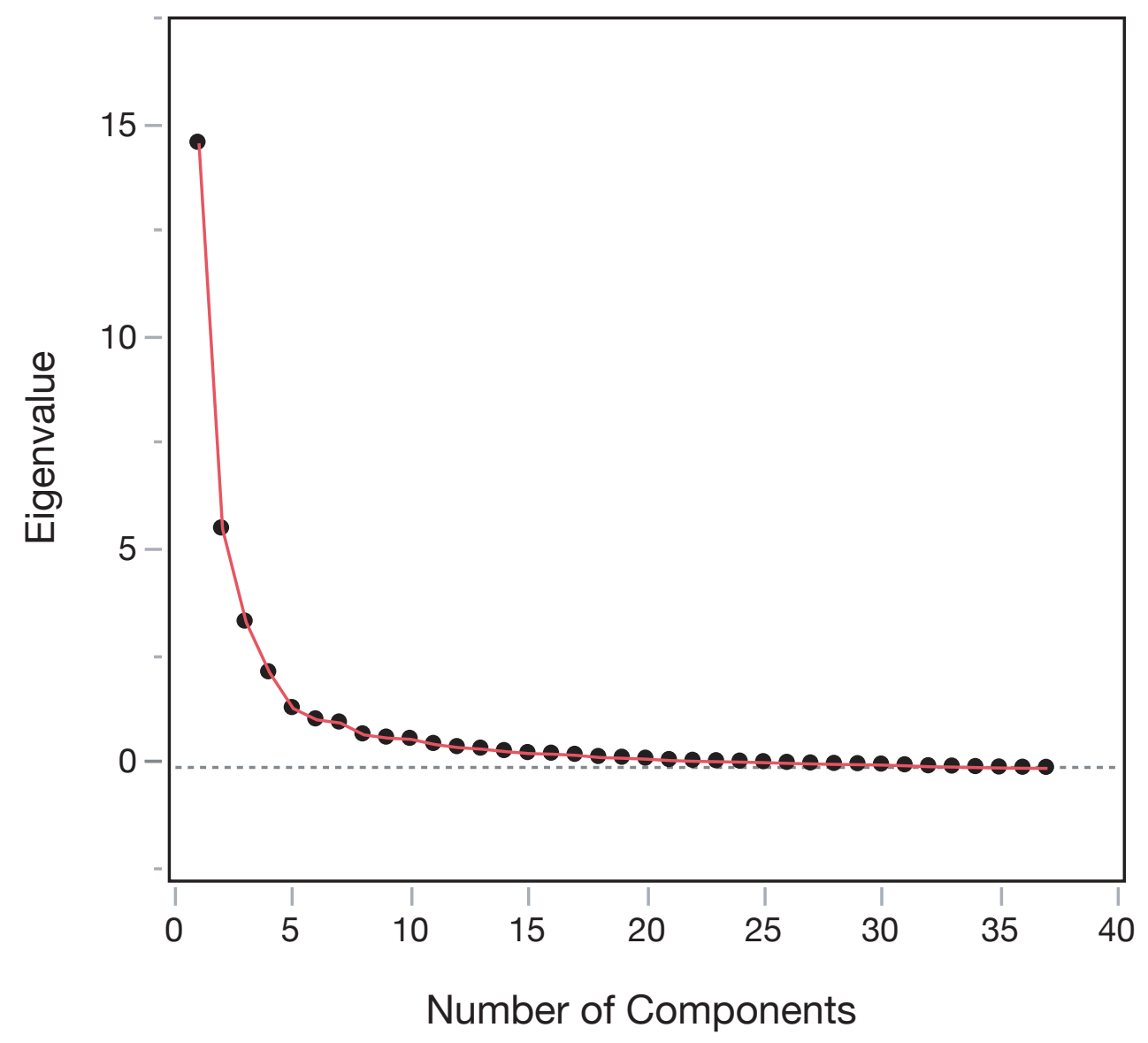



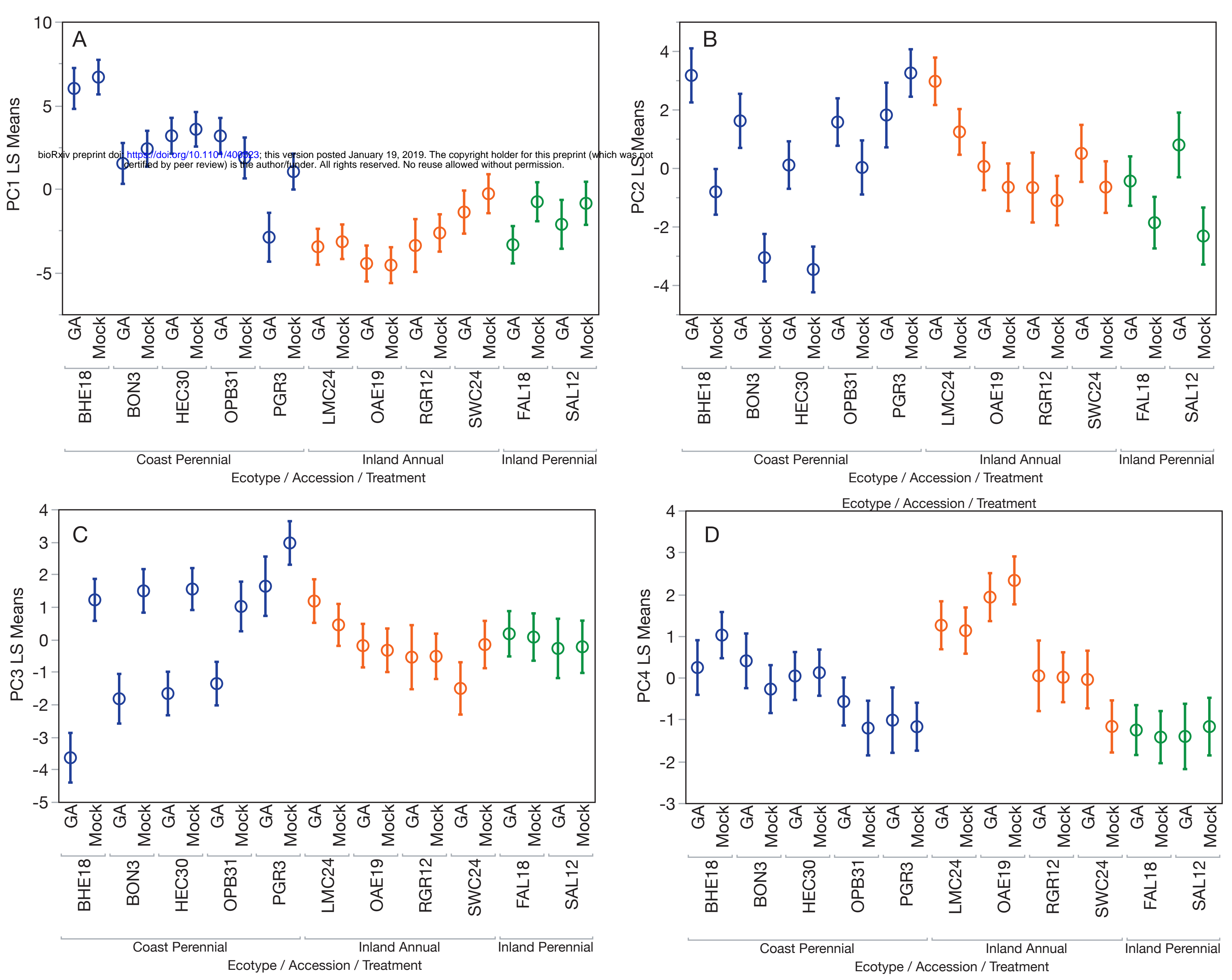
bioRxiv preprint doi: https://doi.org/10.1101/400523; this version posted January 19, 2019. The copyright holder for this preprint (which was not certified by peer review) is the author/funder. All rights reserved. No reuse allowed without permission.

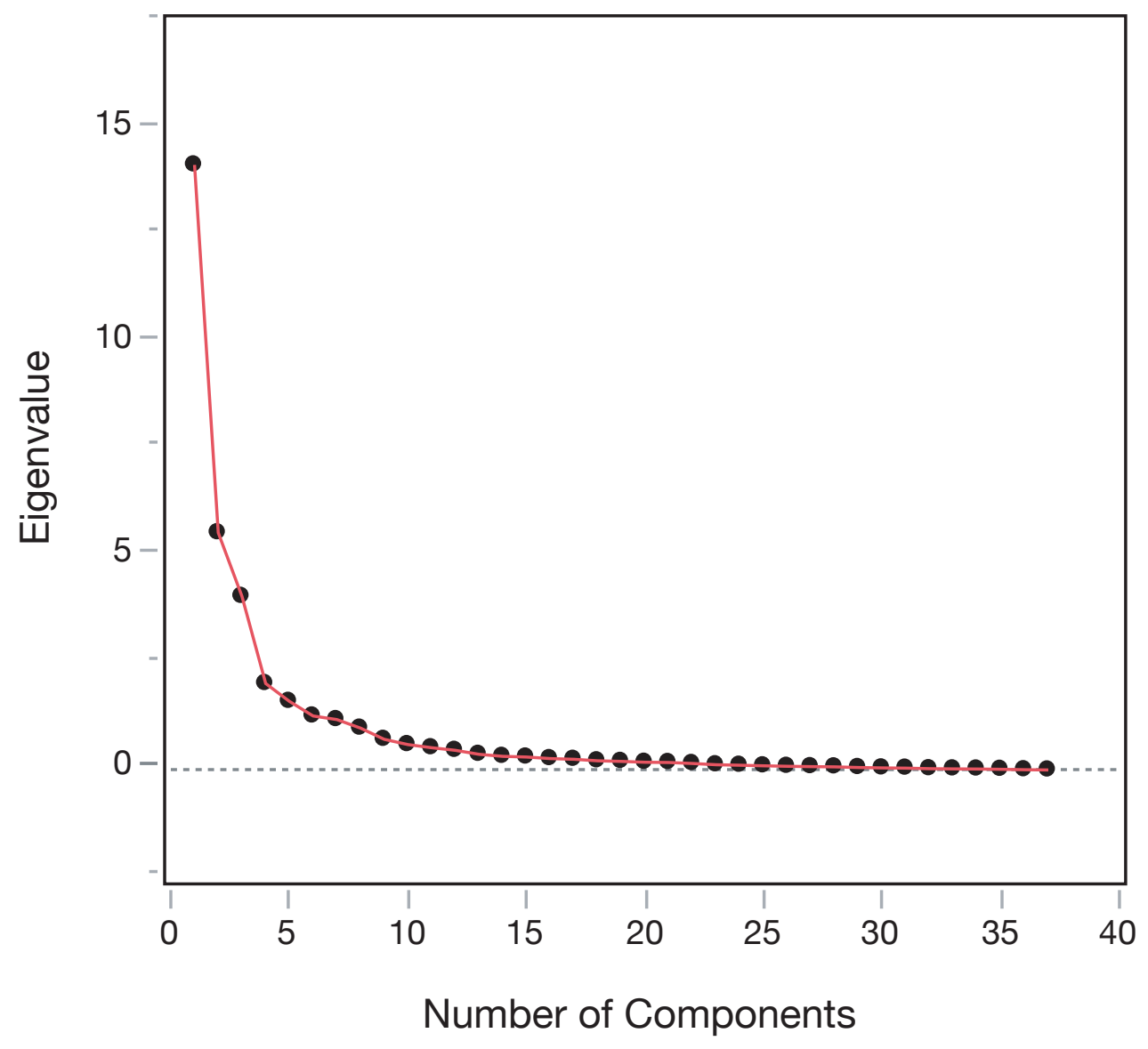

